\title{
Dostoiévski e a Psicologia: o escritor como leitor e objeto da ciência da mente $^{1}$
}

\section{Priscila Nascimento Marques}

FFLCH / Universidade de São Paulo

Resumo: 0 presente artigo busca desdobrar as relações entre literatura e psicologia a partir do caso do escritor russo Fiódor Mikháilovitch Dostoiévski (1821-1881). Inicialmente, abordaremos o interesse do romancista russo pela psicologia de Carl Gustav Carus (1789-1869). A seguir, são descritas algumas apropriações que a "crítica psicológica", isto é, realizada por médicos e psicólogos, fez da literatura dostoievskiana.

Palavras-chave: Literatura russa, Psicologia, F. M. Dostoiévski, C. G. Carus

\begin{abstract}
The present article aims at developing the relations between literature and psychology considering the case of the Russian writer Feodor Mikhailovich Dostoevsky (1821-1881). Initially, the text treats Dostoevsky's interest in the Psychology of Carl Gustav Carus (1789-1869). Then, it deals with some appropriations of Dostoevsky's literature made by the "psychological criticism", i. e. the criticism made by doctors and psychologists.
\end{abstract}

Keywords: Russian Literature, Psychology, F. M. Dostoevsky, C. G. Carus 
Se a literatura dostoievskiana tem sido considerada fonte inesgotável de material para a Psicologia, o interesse de Dostoiévski por essa ciência não pode, por sua vez, ser negligenciado. A possibilidade de que o arcabouço teórico da psicologia possa oferecer visadas críticas originais à literatura dostoievskiana ${ }^{2}$ encontra paralelo na pronunciada curiosidade de Dostoiévski pelos sistemas psicológicos a ele contemporâneos. Belknap, no texto "Dostoiévski e a Psicologia", faz um mapeamento das teorias conhecidas (admiradas ou rejeitadas) por Dostoiévski (Belknap 2002: 131-134). Dentre os nomes citados pelo crítico, o de Carl Gustav Carus (1789-1869) merece destaque em outros trabalhos comparativos, por constar de uma listagem de livros solicitados por Dostoiévski em carta ao irmão (Frank 1999: 238).

A partir de 1854, quando deixa o desterro para servir como soldado raso em Semipalatinsk, Dostoiévski trava contato com o Barão A. E. Wrangel (cf. Grossman 1967: 204-209). Em suas memórias, o Barão trata da amizade entre ambos e acrescenta: "Nós estudamos todos os dias e agora vamos traduzir a Filosofia de Hegel e Psyche de Carus" (apud Gibian 1955: 371). Apesar de malogrado, o intento de realizar tal tradução constitui evidência do interesse de Dostoiévski pela teoria do cientista alemão e justifica as inúmeras menções a Carus em diferentes comentadores da obra e do pensamento dostoievskiano ${ }^{3}$. Carus aliou sua formação médica e espírito investigativo ao vívido interesse pelas ideias de Goethe e Schelling, expoentes do romantismo alemão. Dessa forma, elaborou sua leitura dos fenômenos naturais e das descobertas mais recentes do campo da fisiologia à luz da Ideia Divina e de seu princípio criador. Por tal espírito conciliador, foi descrito por Béguin como "executor testamentário do romantismo filosófico", cuja obra se manteve livre dos “ouropéis de um ocultismo trivial” (Béguin 1991: 173). A principal contribuição apresentada por Carus em seu tratado de psicologia, intitulado Psyche, zur Entwicklungsgeschichte der Seele (1846), consiste na elaboração de uma concepção de inconsciente que atua de modo consoante com o princípio divino:

A chave para uma compreensão da natureza da vida consciente reside na esfera do inconsciente. [...] Num primeiro olhar sobre nossa vida interior, vemos que a maior parte da nossa vida psíquica reside no domínio do inconsciente. Embora estejamos conscientemente informados de apenas algumas 
ideias em um dado momento, nós criamos continuamente milhares de ideias que são completamente inconscientes, desconhecidas no presente, mas, apesar disso, definitivamente existentes. Esta é uma indicação de que a maior parte da vida psíquica repousa na noite do inconsciente. Mais tarde, quando traçamos a notável evolução de uma ideia, devemos ver que a vida do psiquismo pode ser comparada a um grande rio que flui continuamente, iluminado somente em uma pequena área pela luz do sol. (Carus 1970: 1, grifos do autor)

Thomas, em seu estudo sobre o vocabulário de Dostoiévski, aponta para o uso do termo "inconsciente" pelo autor e sugere a comparação das terminologias de Dostoiévski e de Carus, além de aventar a hipótese de que tal uso possa ajudar a explicar o motivo de sua obra antecipar muito da psicanálise (Thomas 1982: 675-676). No campo ideológico, Frank aproxima a insistência de Carus sobre a necessidade de haver um equilíbrio entre as esferas consciente e inconsciente à ideologia do potchvennítchestvo de Dostoiévski, a qual "requeria a fusão de uma intelectualidade inspirada pelas ideias ocidentais do racionalismo e da ilustração com as forças morais inconscientes latentes no âmago ainda não corrompido do povo russo" (Frank 1999: 244). Na esfera literária, tomando particularmente o texto de Crime e castigo, são verificadas apenas três ocorrências do termo "inconsciente", conforme a Concordância ao Crime e castigo de Dostoiévski editada por Atsushi, Yasuo e Tetsuo (1994), sendo que somente uma delas se refere ao protagonista4. Não obstante, é possível observar na própria estrutura da obra, isto é, no seu princípio construtivo, a presença de uma noção de inconsciente próxima àquela expressa por Carus, uma vez que a representação bem-sucedida da subjetividade de Raskólnikov está, em grande medida, atrelada à necessidade de um narrador onisciente, capaz de acessar os sonhos e os "atos gratuitos" desse personagem. A passagem da narração de primeira para terceira pessoa ${ }^{5}$ implica, dentre outras coisas, que a apreensão mais cabal da consciência deve ultrapassá-la para alcançar a seara do inconsciente.

Para caracterizar os universos da consciência e do inconsciente, Carus identifica suas marcas fundamentais. Para ele, a consciência é o domínio da liberdade, ao passo que o inconsciente é o domínio da necessidade: 
Nós logo nos convencemos de dois fatos: o domínio da absoluta necessidade sobre a esfera do inconsciente, e a liberdade que sobrevêm com o advento da consciência. Os opostos, aqueles fatores mais significativos para a compreensão da vida da alma, datam deste estágio da consciência emergente. 0 que quer que se forme inconscientemente em nós, nesse começo, é uma manifestação viva do divino. 0 destino desta manifestação divina jaz fora do controle da existência individual, assim como a mente individual jamais poderá penetrá-la completamente. Nenhum indivíduo pode existir nessa região, porque a vontade pressupõe o entendimento. Mas uma necessidade estranha ao nosso entendimento e à vontade existe incondicionalmente. Sendo a única força determinante para a alma amplamente inconsciente, ela também influencia a liberdade daquela parte da alma que se tornou consciente. Dessa forma, uma vez que toda nossa existência psíquica paira eternamente entre o inconsciente e a consciência, nós constantemente oscilamos, ao longo de toda vida, entre a vontade e a compulsão, a liberdade e a necessidade. (Carus 1970: 55-56, grifos do autor)

O inconsciente é regido por uma necessidade derivada do princípio divino, que desconhece o bem e o mal. Dessa forma, somente a consciência, que é dotada de liberdade, pode inclinar-se ao mal: "o Mal nasceu na terra com o primeiro raio da consciência humana: o Inconsciente da vida cósmica, pura emanação de Deus, não pode estar corrompido, nem se abrir ao mal" (Béguin 1991: 193). Tal entendimento da questão do mal encontra ressonâncias no pensamento de Dostoiévski, especialmente conforme sua apreensão por Nikolai Berdiáiev (1874 - 1948), para quem "a liberdade, degenerando em arbitrariedade, conduz ao mal, o mal ao crime, e o crime, enfim, - por uma fatalidade interior - ao castigo" (Berdiaeff s.d.: 106). É essa liberdade que permite a Raskólnikov elaborar sua teoria dos homens extraordinários e questionar-se sobre o direito de matar. Para Berdiáiev, esse direito não existe, pois, "conforme o prova uma experiência conduzida de maneira imanente, a natureza humana é criada à imagem de Deus e porque tudo possui, em si, um valor absoluto" (Berdiaeff s.d.: 115-116). Wolf vê na liberdade a fonte da motivação ambígua para o crime de Raskólnikov: "O crime de Raskólnikov é o ato de um humano perplexo por sua escolha e incapaz de escapar de seu livre-arbítrio" (Wolf 1997: 180). Ainda de acordo com Wolf, a escolha por um narrador onisciente em relação a Raskólnikov contribui para a representação do herói como alguém livre, pois o protagonista é acompanhado pelo narrador, sem que ele se antecipe ou o justifique. 
Outro ponto que aproxima o romancista russo do psicólogo alemão refere-se ao universo dos sentimentos, em particular do amor. Para Carus, o sentimento é responsável pela captação da ideia e se constitui como uma ligação para o inconsciente. Tudo que fermenta para além dos limites da consciência "sobe, com um acento muito particular, da noite inconsciente para a luz da vida consciente; e a esta melodia, a esta maravilhosa confidência do Inconsciente ao Consciente chamamos sentimento" (Carus apud Béguin 1991: 184). É por meio do sentimento que o ser humano pode alcançar as regiões mais profundas em que todas as almas estão em relação com sua unidade comum, e o amor, na condição de forma mais elevada do sentimento, é "o primeiro resgate da existência separada, o primeiro passo da volta ao Todo" (Carus apud Béguin 1991: 185). Para Gibian,

Seu elogio do amor como o encontro das partes consciente e inconsciente da alma, por meio do qual o humano começa a repudiar seu egoísmo e é capaz de retornar à comunidade com outros seres humanos, bem como chegar à percepção suprarracional do universal e do divino, também é análogo à concepção de Dostoiévski personificada pelas mais elevadas formas de amor em Crime e castigo, $O$ idiota e Os irmãos Karamázov. (Gibian 1955: 373)

Um aspecto importante da vida psíquica, caro a ambos, refere-se ao papel dos sonhos. Em Carus, eles possibilitam uma união íntima entre consciente e inconsciente, constituem, assim, "a atividade da consciência na alma que volta à esfera do inconsciente" (Béguin 1991: 186, grifos do autor). Já a sua função consiste na "conquista da consciência pelo inconsciente no êxtase ou no afastamento de si mesmo, pode, na realidade, dentro de limites, nos dar vida e força" (Carus 1970: 66-7). No caso de Crime e castigo, as análises de Katz demonstram como os sonhos de Raskólnikov reelaboram conteúdos retirados do cotidiano e os reinterpretam à luz do inconsciente, configurando-se, desse modo, como o palco da intersecção consciência/inconsciente, conforme propõe Carus. Em sua interpretação do primeiro sonho (do espancamento de uma égua por seu dono, Mikolka), por exemplo, Katz lembra que os encontros que o precedem fornecem o contexto que explica a reação traumática de Raskólnikov. Tal contexto é constituído pelo encontro com Marmieládov na taverna, o recebimento da carta escrita por sua mãe e, por fim, o 
testemunho da cena em que um senhor assedia uma jovem garota embriagada. De modo geral, todas essas situações despertam uma resposta emocional espontânea de compaixão por parte de Raskólnikov, ainda que essa seja imediatamente substituída por um desinteresse intelectual e crescente raiva (Katz 1984: 96). Assim, "seu subconsciente revela, tanto para o sonhador quanto para o leitor, o Raskólnikov 'real' - a criança que sente compaixão pela vítima e hostilidade pelo vitimizador, e que faz o profundo questionamento" (Katz 1984: 98).

Outro ponto abordado por Carus, e que pode ser tratado comparativamente, referese à patologia. Na condição de pensador monista, Carus não pode ver o adoecimento como um processo que atinge somente o corpo ou uma parte dele. E mesmo na busca pela cura têm papel fundamental as forças inconscientes:

Quando diante de desvios da boa saúde, ele [o inconsciente] sempre nos conduz de volta ao centro. Assim, podemos ver que a existência orgânica inconsciente, embora desconheça a doença, sustenta tudo que combate as enfermidades e trabalha constantemente para o restabelecimento da saúde. A isso se costuma dar o nome de "poder curativo da natureza". (Carus 1970: 71)

Frank assinala que a imagem de uma consciência reguladora, cuja distorção provoca um literal "adoecimento" do ego, tornou-se um importante tópico dos grandes romances de Dostoiévski (Frank 1999: 245). Para Gibian, Dostoiévski apresenta concepção semelhante sobre as doenças em suas personagens, tais como Ippolit, Lisa Khokhlakova, Iliúcha, Raskólnikov e outros (Gibian 1955: 375). No caso do protagonista de Crime e castigo, as justificativas objetivas (calor, cansaço, bebida) apresentadas para sua fraqueza apenas mascaram a causa verdadeira, isto é, "a rebelião de seu subconsciente contra todo seu modo de vida" (ibidem). Ainda conforme o mesmo crítico, Raskólnikov aparece como exemplo do que Carus chama de "doença da vontade", caracterizada por oscilações comportamentais de gênese inconsciente, bem como da "apatia animalesca", derivada do atrofiamento do inconsciente (idem: 376s).

Apesar das possíveis aproximações, os críticos se mostram cautelosos em falar de uma "influência" do pensamento de Carus sobre o de Dostoiévski. Frank reconhece no 
interesse do romancista pela Psyche de Carus uma tendência permanente de seu pensamento. Para ele, Dostoiévski “conservará para sempre a ávida curiosidade por obras eruditas que, ao mesmo tempo em que demonstram pleno conhecimento e domínio das últimas teses da ciência moderna e da filosofia, persistem na tarefa de defender o idealismo e uma visão religiosa do mundo" (Frank 1999: 245). Já Gibian discute a possibilidade de ambos terem chegado de forma independente a descobertas semelhantes, e defende que Psyche tenha fortalecido as crenças de Dostoiévski sobre o funcionamento da mente humana, além de levá-lo a desenvolver suas ideias sobre a importância do inconsciente (Gibian 1955: 382). Dessa forma, é possível observar que a atenção dedicada pelo romancista à ciência psicológica deixou marcas na formação tanto do Dostoiévski-pensador quanto do Dostoiévski-artista.

A outra face da relação entre Dostoiévski e a Psicologia, certamente mais conhecida, diz respeito à extensa "crítica psicológica" dedicada à obra e/ou à vida do romancista russo. As primeiras tentativas de análise psicológica de sua literatura partiram de um viés marcadamente conteudista. Para esses críticos-psicólogos, texto literário e prontuário médico são produções que despertam um interesse equiparável. Assim, psicólogos e médicos perceberam nos "romances-prontuário" de Dostoiévski um verdadeiro manancial de tipos psicopatológicos. Segundo Gomide, Dostoiévski

[...] além de ser considerado o "mais russo" dos escritores e, portanto, o melhor exemplo de nacionalização nas letras [...]; ou aquele que apresentava a biografia mais sofrida, o que satisfazia uma imagem de escritor-mártir condizente com o que demonstravam pateticamente os manuais sobre o temível "niilismo" russo; ou, ainda, o melhor exemplo da união entre temas românticos e novidade naturalista, era porque em Dostoiévski o material para a pesquisa psicopatológica emanava com mais vigor. (Gomide 2008: 122-123)

Para Ossip-Lourié, por exemplo, o valor literário das obras de Dostoiévski é menor do que sua importância para a psicopatologia e antropologia criminal6. Já o neurologista americano Joseph Collins recorreu a um grande número de epítetos para classificar Dostoiévski: "profeta, pregador, psicólogo, patologista, artista e indivíduo" (Collins 1923: 
61). Pondera que, embora ele não tivesse formação para ser considerado um especialista nesses assuntos, tal era sua capacidade de descrever

muitos dos transtornos nervosos e mentais, tais como mania e depressão, as psiconeuroses, histeria, estados obsessivos, epilepsia, insanidade moral, alcoolismo e aquela constituição mental e moral chamada 'degenerescência' [...] que alienistas reconhecem em suas descrições obras-primas assim como um pintor reconhece o apogeu de sua arte com Giotto e Velásquez. (Collins 1923: 61-2)

Outra característica da crítica psicológica é a junção de fatos biográficos e conteúdos da obra ficcional na interpretação. Ossip-Lourié e Joseph Collins, por exemplo, entremeiam suas narrações sobre a vida de Dostoiévski com análises de suas principais obras. E, uma vez que os romances eram tomados por prontuários clínicos, cabe a esses críticos chegar a alguma conclusão diagnóstica. Eis algumas tentativas:

Raskólnikov é louco ou criminoso? Quem resolverá essa questão? Em todos os casos, ele não é nem um criminoso nato nem um louco nato, mas, antes, aquilo que Lombroso chama de criminoso de ocasião. Seja loucura ou crime, seja loucura e crime, a causa é, acima de tudo, social. Ela está ligada, em parte, às más condições materiais em que Raskólnikov havia vivido durante muitos meses; é o produto complexo de influências múltiplas - físicas ou psicológicas - tais como: preocupações, receios, inquietudes, devaneios, isto é, provém, antes de tudo, da injustiça social. (Ossip-Lourrié 1905: 172)

o Crime e Castigo de Dostoiewsky é, como diz muito justamente M.Vogüé, o estudo mais profundo de psicologia criminal depois de Macbeth. As discussões eternizam-se em torno do seu principal personagem Raskolnikoff, cujo diagnóstico é difícil de ser feito. É um louco ou um criminoso? Para Grasset, é um semidoido "bom e generoso", mas "melancólico, sombrio, orgulhoso, altivo, hipocondríaco" (Luiz Ribeiro do Valle apud Gomide 2008: 124)

A dificuldade de se estabelecer um diagnóstico definitivo para um personagem como Raskólnikov é reconhecida pelos estudiosos e os leva a conclusões díspares. A justificativa social e material de Ossip-Lourié parece excessivamente determinista se observarmos que Dostoiévski representou, no mesmo contexto miserável, um personagem como Razumíkhin, 
personificação da razão saudável e longe de estar acometido por tantas desordens mentais. Já a tentativa de Luiz Ribeiro do Valle demonstra a necessidade de um verdadeiro arsenal de itens sintomatológicos para compreender minimamente o protagonista de Crime e castigo. Ainda assim, vale observar que esses comentadores não passaram à margem da complexidade psicológica do personagem. A própria abundância de nomenclaturas evidencia tal sensibilidade.

Quando a psicanálise coloca o inconsciente na pauta das discussões sobre o psiquismo humano, dando-lhe uma formulação original, a literatura de Dostoiévski permanece uma importante fonte. Abandonando a distinção rígida entre normal e anormal, Janko Lavrin observa:

É característico de Dostoiévski preocupar-se principalmente com aquela área transitória da nossa consciência em que o irracional suplanta o racional, o inconsciente suplanta o consciente, o "fantástico" suplanta o real. Ele é um mestre supremo somente nessa fronteira mutável, na qual nada é determinado, fixo e firme, em que "todas as contradições existem lado a lado". (Lavrin 1920: 46)

A percepção de que a obra dostoievskiana lida com contradições da condição humana torna-se mais aguçada, uma vez livre das rígidas categorizações psicopatológicas e dos mais variados determinismos. Além disso, Lavrin observa que o ofício de Dostoiévski não era a ciência, mas a arte, de modo que, seu interesse por casos psicopatológicos só existia na medida em que eles "refletiam o processo mais profundo, espiritual da mente do homem" (Lavrin 1920: 45). Ainda assim, as explicações psicanalíticas não escapam do biografismo. 0 ensaio de Freud sobre Dostoiévski é dedicado essencialmente à análise da origem da neurose do romancista a partir de fatos de sua vida e de elementos de suas obras (o romance Os irmãos Karamázov, nesse caso, constitui a manifestação do desejo parricida inconsciente de Dostoiévski). No entanto, as pretensões de Freud não estão escamoteadas. Logo no início de seu ensaio, o autor distingue quatro facetas na personalidade de Dostoiévski: o artista-criador, o neurótico, o moralista e o pecador. Sobre a primeira delas, afirma: 
O artista criador é o menos duvidoso: o lugar de Dostoiévski não se encontra muito atrás de Shakespeare. Os irmãos Karamassovi [sic] são o mais grandioso romance jamais escrito, quanto ao episódio do Grande Inquisidor, um dos pontos culminantes da literatura mundial, dificilmente qualquer valorização será suficiente. Diante do problema do artista criador, a análise, ai de nós, tem de depor suas armas. (Freud 1996: 183)

Assim, a análise freudiana busca interpretar o psiquismo do autor, sem almejar, contudo, compreender seu gênio literário ou decifrar definitivamente sua obra, a qual aparece apenas como auxiliar no desvelamento dos recônditos inconscientes do romancista. Não obstante, há outras tentativas de interpretação de personagens dostoievskianas tão comprometidas com a descoberta de um sujeito psicanalítico que, para tanto, não hesitam em colocar o personagem no divã e identificar nele desejos incestuosos e homossexuais, como é o caso de Florance no artigo "The neurosis of Raskolnikov" (Florance 1961: 57-76).

Discussões posteriores acerca da literatura dostoievskiana esforçaram-se para garantir uma maior autonomia ao campo estético e trabalhar com o texto literário sem forçar o estabelecimento de relações entre fatos da vida do autor e o conteúdo de sua obra. Belknap, por exemplo, afirma:

Em geral, os leitores de Dostoiévski têm tido dificuldade para explicitar a psicologia própria deste autor. Normalmente eles a subentendem a partir do comportamento ou do discurso de seus personagens - um grande engano, porque a ficção de Dostoiévski existe por si mesma, não se constitui como uma emanação de seu espírito. (Belknap 2002: 136-7)

Belknap defende que a explicação para Dostoiévski ter-se utilizado deste ou daquele conteúdo psicológico deve ser literária e não biográfica, uma vez que "Dostoiévski não utiliza raisonneurs, ou porta-vozes para suas próprias ideias, embora alguns comentários se aproximem mais delas do que outros. Seu significado deve emergir da interação das falas e ações de muitos personagens" (Belknap 2002: 137). Mais importante, Belknap conclui que não se pode separar esse conteúdo psicológico do todo romanesco; a obra deve ser vista em 
sua totalidade e organicidade própria. Ao desenvolver as relações entre amor e violência, alinhavadas pelo poder, Belknap conlcui:

Para Dostoiévski, as vítimas tornam-se vencedores. Se a tragédia fala da fraqueza do forte, os romances, ou pelo menos esse tipo de romance, trata do poder do fraco. Essa ideia não foi original com Dostoiévski; Jesus, por exemplo, tivera-a antes, e Dostoiévski era profundamente cristão. Mas sua contribuição à história da psicologia não reside na originalidade de suas descobertas. Está na forma pela qual ele coloca as ideias de seu tempo diante do tipo de leitor que intelectualiza apaixonadamente um mundo ficcional. Ele transformou o romance psicológico em um instrumento filosófico ao explorar as relações entre as ideias dos personagens e suas pulsões e personalidades. E, uma vez que seus imperativos literários, religiosos, sociais e psicológicos se reforçavam mutuamente, ele pôde controlar todos os elementos de sua ficção e alcançar uma totalidade de impacto que tornou sua visão da humanidade particularmente contagiosa. Ele nos faz sentir a psicologia como parte do todo romanesco. (Belknap 2002: 146)

Uma forma mais radical de negação da leitura do romance como prontuário aparece na completa rejeição da psicologia como elemento significativo para o texto literário. Wellek e Warren (1962), nas derradeiras linhas do capítulo sobre Literatura e Psicologia, afirmam categoricamente a prescindibilidade dessa ciência à arte, já que ela, em si mesma, não tem qualquer valor artístico ${ }^{7}$. Ainda que reconheça a possibilidade de a psicologia ter aguçado a capacidade de observação do artista, ela "em si própria [...] é apenas preparatória do ato de criação; e, na obra em si própria, a verdade psicológica só terá valor artístico se realçar a coerência e a complexidade: numa palavra, se for arte" (Wellek/ Warren 1962: 111). Tal separação intransigente entre forma literária e conteúdo psicológico foi questionada por Todorov na seguinte afirmação sobre a crítica dostoievskiana:

Dostoiévski interessou-se apaixonadamente pelos problemas filosóficos e religiosos de seu tempo; transmitiu esta paixão aos seus personagens e ela está presente em seus livros. De saída é raro que os críticos falem de "Dostoiévski, o escritor" [...] todos apaixonam-se por suas "ideias", esquecendo-se que elas se encontram no interior de romances. Aliás, admitindo-se que mudem de perspectiva, não se evitaria o perigo, apenas se inverteria: podemos estudar a "técnica" em Dostoiévski abstraindo os grandes debates ideológicos que animam seus romances [...]? Propor hoje uma leitura de Dostoiévski 
é, de certo modo, lançar um desafio: deve-se chegar a ver simultaneamente as "ideias" de Dostoiévski e sua "técnica" sem privilegiar indevidamente uma ou outra. (Todorov 1980: 130)

Assim, ressalta-se a importância de se pensar o estudo da literatura em seus potenciais diálogos com outras esferas do conhecimento, levando em conta o universo estético e ideológico do autor estudado. Com efeito, muitas das análises psicológicas da literatura dostoievskiana desprezaram seu valor artístico em favor de uma suposta verdade psicológica apresentada por ela. Dessa forma, imputam um objetivo alheio e exterior às obras, ao mesmo tempo em que negligenciam suas características formais mais fundamentais e seu status ficcional. Não se pode deixar de observar, contudo, como lembram Belknap e Todorov, que tal crítica toca em pontos efetivamente pertinentes ao universo literário dostoievskiano, isto é, deriva de elementos presentes em sua obra. Ademais, com este artigo buscou-se resgatar a outra face da relação entre literatura e psicologia, que diz respeito ao interesse, frequentemente grande, de artistas pela ciência da mente. Temos em Dostoiévski, muito anteriormente à conhecida inclinação das vanguardas do século XX pela Psicanálise, um bom exemplo disso.

\section{Notas}

${ }^{1} 0$ presente artigo é oriundo da pesquisa Polifonia e Emoções: um estudo sobre a construção da subjetividade em Crime e castigo de Dostoiévski (Marques 2010), que obteve financiamento da Fundação de Amparo à Pesquisa do Estado de São Paulo (Fapesp).

2 Para Gomide "[...] limitar-se a apontar as contradições entre romance russo e antropologia criminal, na história das ideias e dos gêneros literários, é tarefa infrutífera. 0 mais importante é verificar como essa forma de apropriação consegue atingir problemas literários relevantes a partir dos novos usos e significados de que

N. ${ }^{\circ} 37$ - 12/ 2017 | 147-162 - ISSN 2183-2242 | http:/dx.doi.org/10.21747/21832242/litcomp37a7 
passam a dispor em novo contexto, frente a novo objeto de estudos. A leitura criminal do romance russo representa limites evidentes, mas também algumas entradas originais" (Gomide 2008: 131).

3 Por exemplo, Wellek 1970: 314; Belknap 2002: 134; Frank 1999: 238 e 241-245; Gibian 1955; Thomas 1982: 675-6; Katz 1984: 86-88; Smith e Isotoff 1935. Deste último texto foi encontrada somente a referência, sem que pudéssemos ter tido acesso ao seu conteúdo: Smith, Stephenson / Isotoff, Andrei, 1935, "The abnormal from within: Dostoevsky". Studies in Psychology, I, Bull. 7, republicado em Psychoanalytic Review 22, 1935.

4 "Seu tremor nervoso transbordou num tremor algo febril; chegou a sentir calafrio; ficou com frio em meio a todo aquele calorão. Como quem faz esforço, começou de modo quase inconsciente, movido por alguma necessidade interior, a fixar o olhar em todos os objetos que ia encontrando, como se estivesse em redobrada procura de distração, porem isso lhe saía mal e a todo instante ele caía em meditação" (Dostoiévski 2001: $68 s)$.

${ }^{5}$ Dostoiévski chegou a elaborar duas versões em primeira pessoa, antes de chegar ao narrador onisciente em terceira pessoa da versão final de Crime e castigo. 0 processo de construção de Crime e castigo é relatado por Frank no capítulo "De novela a romance" de Dostoiévski: os anos milagrosos (1865-1871), cf. Frank 2003: 123142)

6 "As obras de Dostoiévski devem ser estudadas menos do ponto de vista literário do que do ponto de vista da psicopatologia e da antropologia criminal. Todas as formas de nevrose, epilepsia, obsessão, degenerescência são apresentadas" (Ossip-Lourié 1905: 180).

7 “A psicologia - no sentido de uma consciente e sistemática teoria do espírito e do funcionamento deste - é desnecessária à arte e não tem, em si, valor artístico" (Wellek/ Warren 1962: 110).

N. ${ }^{\circ} 37$ - 12/ 2017 | 147-162 - ISSN 2183-2242 | http:/dx.doi.org/10.21747/21832242/litcomp37a7 


\section{Bibliografia}

Atsushi, Ando / Yasuo, Urai / Tetsuo, Mochizuki (1994), A Concordance to Dostoevsky's Crime and Punishment, Sapporo, The Slavic Research Center, Hokkaido University.

BÉGUIN, Albert (1991), "Le mythe de l'inconscient (Carl-Gustav Carus)", in L'âme romantique et le rêve: essai sur le romantisme allemande et la poésie française, Paris, José Corti, 166-198.

Belknap, Robert L. (2002), "Dostoevskii and Psychology", in LEATHERBARROW, W. J. The Cambridge Companion to Dosotevskii, Cambridge, Cambridge University Press, 131-147.

Berdiaeff, Nicolai (s.d.), O espírito de Dostoiévski. Tradução Otto Schneider, Rio de Janeiro, Panamericana.

Carus, Carl-Gustav (1970). Psyche: On the Development of the Soul. Dallas, Texas: Spring Publications.

Collins, Joseph (1923), The Doctors Look at Literature, Nova Iorque, George H. Doran Company.

Dostoiévski, Fiódor Mikháilovitch (2001), Crime e castigo, Tradução Paulo Bezerra, São Paulo, Editora 34.

Florance, Edna (1961), "The neurosis of Raskolnikov" in WASIOLEK, Edward (ed). Crime and Punishment and the Critics, San Francisco, Wadsworth Publishing Company, 57-77.

Frank, Joseph (1999), Os anos de provação (1850-1859). Tradução Vera Pereira, São Paulo, Edusp.

-- (2003) Os anos milagrosos (1865-1871), Tradução Geraldo Gerson de Souza, São Paulo, Edusp.

Freud, Sigmund (1996), "Dostoiévski e o parricídio (1928[1927])" in O Futuro de uma ilusão, O mal-estar na civilização e outros trabalhos, Rio de Janeiro, Imago.

Gibian, George (1955), "Traditional Symbolism in Crime and Punishment", PMLA, v. 70, n 5, 
Modern Language Association, 979-996.

Gomide, Bruno Barretto (2008), "Dostoiévski sob a lente psicopatológica: antropologia criminal e literatura russa no Brasil" in Caderno de literatura e cultura russa, São Paulo, Ateliê Editorial, 119-136.

Grossman, Leonid (1967), Dostoiévski artista, Rio de Janeiro, Civilização Brasileira.

Katz, Michael R (1984), Dreams and the Unconscious in Nineteenth Century Russian Fiction, Hanover / London, University Press of New England.

Lavrin, Janko (1920), Dostoevsky and His Creation: A psycho-critical study, Londres, W. Collins Sons \& CO.

Marques, Priscila Nascimento (2010), Polifonia e emoções: um estudo sobre a construção da subjetividade em Crime e castigo de Dostoiévski, Dissertação de Mestrado em Letras, Faculdade de Letras, Filosofia e Ciências Humanas, Universidade de São Paulo < http://www.teses.usp.br/teses/disponiveis/8/8155/tde-26082010-144511/pt-br.php> (último acesso em 27/07/2017).

Ossip-Lourié (1905), La psychologie des romanciers russes, Paris, Félix Alcan.

Thomas, George (1982), "Aspects of the Study of Dostoevsky's Vocabulary", The Modern Language Review, v. 77, nº 3, Modern Humanities Research Association, 670-678.

Todorov. Tzvetan (1980), "Notas de um subterrâneo", in Os gêneros do discurso, São Paulo, Martins Fontes, 129-153.

Wellek, René (1970), "A sketch of the history of Dostoevsky criticism", in Discriminations: further concepts of criticism, New Haven and London, Yale University Press, 304-326.

Wolf, Peter Mcguire (1997), Dostoevsky's Conception of Man: Its Impact on Philosophical Antropology, Tese de Doutorado em Literatura e Filosofia - Pennsylvania State University. 
Priscila Marques

Priscila Nascimento Marques é psicóloga pela Universidade Presbiteriana Mackenzie e mestre e doutora em literatura e cultura russa pela Faculdade de Filosofia, Letras e Ciências Humanas da Universidade de São Paulo. Atualmente realiza estágio de pós-doutoramento (com financiamento Fapesp, processo 2015/17830 -1) na mesma instituição. Realiza traduções e estudos da obra de F. M. Dostoiévski e de L. S. Vigotski. 